\title{
Cell Therapy Manufacturing and Quality Control: Current Process and Regulatory Challenges
}

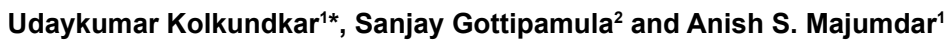 \\ ${ }^{1}$ Stempeutics Research Pvt. Ltd, Bangalore, India \\ ${ }^{2}$ Stempeutics Research Pvt. Ltd, Manipal, India
}

\begin{abstract}
Mesenchymal stromal cells (MSC) are multipotent stem cells that have been isolated from multiple tissue sources and are currently being used to demonstrate their therapeutic efficacy against various clinical indications. Dramatic increase in the use of MSCs for tissue engineering applications and in regenerative medicine in past two decades raises an increasing demand for cGMP (current Good Manufacturing Practice) based large-scale manufacturing process of MSCs and characterization of these cells. The challenge is to assure the safety and high-quality of cells that will ultimately be therapeutically effective. GMP compliance processing such as cell culture, expansion and cryopreservation is mandatory for making the cell therapy effective. MSCs from various tissue sources should be cultured for scale-up according to regulatory compliance to optimize culture conditions and to ensure the safety of these manufactured cell populations. This review describes cGMP compliances and manufacturing process of bone marrow derived MSCs; specifically in the context of establishing the process flow and in-process controls for the manufacturing process. Importantly, this review highlights the current manufacturing challenges and opportunities for process improvisation and its relevance's for MSCs therapeutics potential.
\end{abstract}

Keywords: Mesenchymal stromal cells; Large-scale production process; Cell bank qualifications; cGMP

\section{Introduction}

Advanced cellular therapy products represent a new paradigm of bio-regenerative medicine using MSCs as one of the cell populations to meet with unmet medical need. The application of MSCs for cellbased therapies is in cognitive phase of development and their ability of multipotency, immunomodulatory, proliferation capacity and genomic stability are critical for achieving therapeutic success. On the other hand, global stem cell market expectations are raised constantly and providing more conducive environment for future growth [1-3]. The effectiveness of MSC therapy is based on identification of CD markers and the relationship of these markers to the functional status of the cells as well as the culture conditions used to isolate or scale-up of MSCs product. Furthermore, due to extensive expansion potential and their broad, mesodermal differentiation as well as their immunomodulatory capabilities and secretion of numerous paracrine tropic factors which modulate inflammation, remodelling and regeneration of damaged tissue?

The expansion ability of MSCs is also directly proportional to determine the cell dose and number of administration required for specific disease indications. From the published literature it appears that about 0.5 to $5 \times 10^{6}$ cells $/ \mathrm{Kg}$ body weight are required depending on the conditions for which the cell would be used. This tremendous cell requirement actually necessitates the large-scale manufacturing of cell therapy dose according to the cGMP [4]. Implementing the cGMP amicable production process and scale-up is extensively important to deliver cells of high quality and purity. Meeting the current GMP standards require critical review of the production process to ensure the safety and reproducibility of the process and assays to determine the identity, purity as well as potency of the therapeutic product. Development of cell therapy product (CTP) begins with an idea generation and supportive literature survey which is then followed up with multiple stages of developmental phases such as basic research, discovery, in vitro safety studies, pre-clinical and clinical phases (Phase-I, II, \& III) and regulatory clearance ultimately to product launch. Figure 1 shows a clinical process map and its interaction with process stringency with an incremental increase of standards in system as well as in product and process controls as the CTP is moving from one clinical phase to next. However, the traditional bio-tech products rely mostly at the quality of the purified secreted recombinant proteins $[5,6]$.

Cell therapy bio-processing involves the usage of numerous in-put materials to produce a complex and viable stem cell product. Therefore, developing a unique bio-processing model with novel production process is challenging for the nascent cell therapy manufacturing industries and requires utilizing bioprocessing experiences and solutions for the progressing towards GMP compliance large-scale MSC production. To date, large-scale production is typically achieved using two dimensional (2D) tissue culture vessels-an expensive, open and time-consuming process. Traditional bioreactors may be the right solution for closed production process of MSC but scale-up protocols still require optimization, and bioreactors cannot be used for adherent stem cells unless microcarriers become a viable technology. The researchers are evaluating the utility of a stirred-tank bioreactor in combination with microcarriers for Mesenchymal stem-cell expansion and comparing the characteristics of the manufactured cells with those grown in standard 2D cultures. In this review, we describe the current knowledge and experience of developing large-scale production of BM MSCs, challenges and controls for GMP compliances and safety

*Corresponding author: Udaykumar Kolkundkar, Stempeutics Research Pvt. Ltd, Akshay Tech Park, No: 72 \& 73, 2ndfloor, EPIP Zone, Phase-I Area, Whitefield, Bangalore, India, Tel: +91-080-39992400; Fax: +91-080-39992402; E-mail: uday.kumar@stempeutics.com

Received July 04, 2014; Accepted September 06, 2014; Published September 08,2014

Citation: Kolkundkar U, Gottipamula S, Majumdar AS (2014) Cell Therapy Manufacturing and Quality Control: Current Process and Regulatory Challenges. J Stem Cell Res Ther 4: 230. doi:10.4172/2157-7633.1000230

Copyright: (c) 2014 Kolkundkar U, et al. This is an open-access article distributed under the terms of the Creative Commons Attribution License, which permits unrestricted use, distribution, and reproduction in any medium, provided the original author and source are credited. 


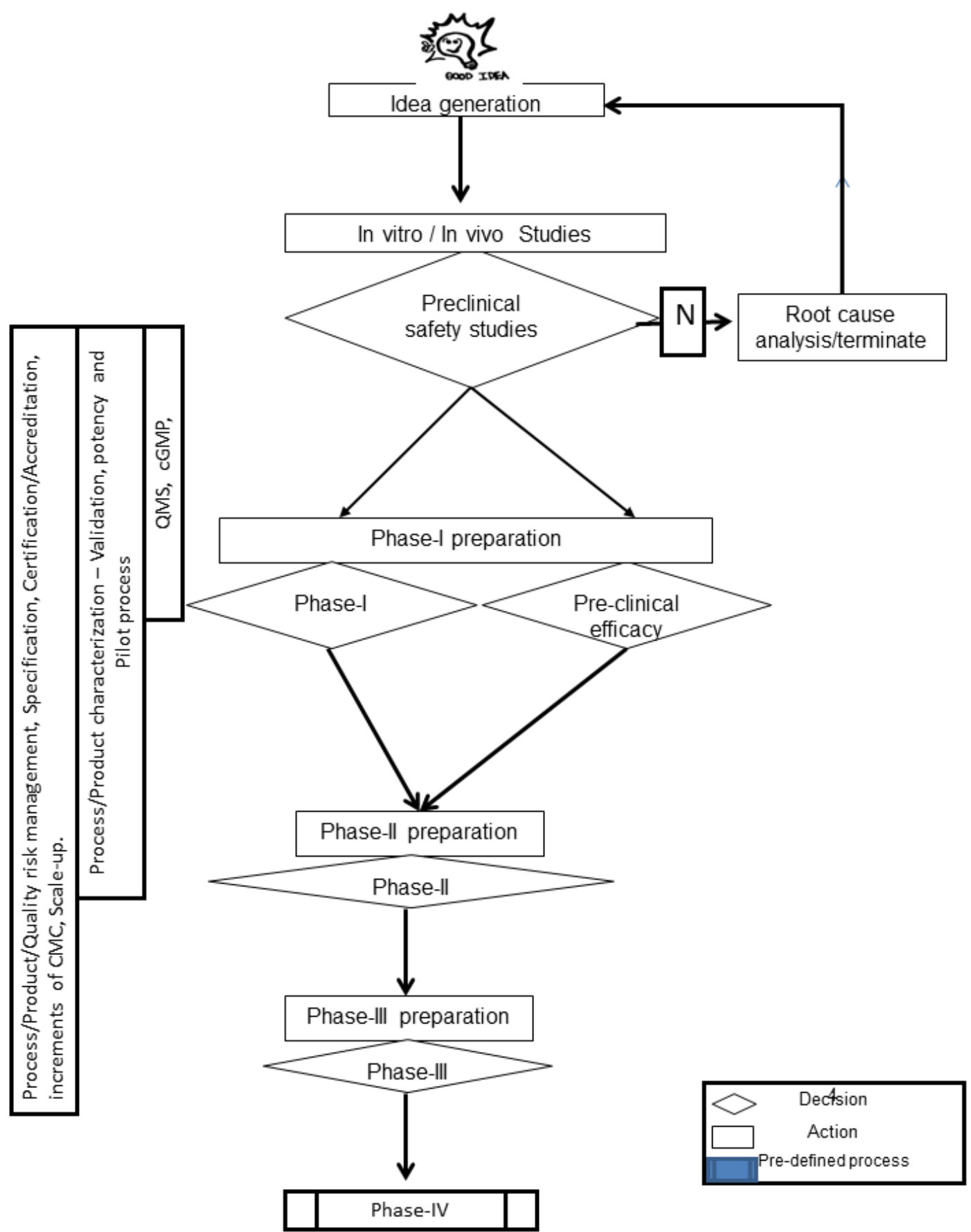

Figure 1: Clinical process map-Developing Mesenchymal Strom Cell therapy product for clinical process manufacturing and its integration into product characterization. Abbreviation: CMC: Chemistry, Manufacturing and Controls; cGMP: current Good Manufacturing Practice, QMS: Quality Management System.

requirements. Besides, we summarize the key translational issues, scale-up challenges and key variables, in-process controls, based on the available literature as well from our own experiences.

\section{Production Process}

The recent success in the use of MSC therapy has increased the demands to produce several hundred to thousand billions of MSCs per batch to satisfy the clinical trial requirements via large-scale expansion, while adhering to GMP compliances. These GMP practices ensure that the product is safe, consistent, effective and of good quality. Although substantial progress has been made in the production process for MSCs but still there is great need to identify and fill the gaps to meet successful GMP compliances. Current production process uses multilayer vessels such as Cell STACKS (CS) (Corning, Corning, NY, USA) or Cell Factory (CF) (Nunc, USA) that could be stacked in the incubators. However, in terms of GMP requirements, these processes are not fully closed and require a class A cabinet for each manipulation step. Therefore, the development and use of closed automated devices are an important step 
for facilitating MSC expansion under GMP compliance. For simpler and safer processes, a fully closed and automated bioreactor must be used. The main criteria for growing MSCs in bioreactors are a large ratio of surface area to volume, a closed system, automated inoculation and harvesting, and automated control of culture parameters. Different designs of bioreactors-parallel-plate, hollow-fiber, or micro-fluidic [7] could help improve these criteria. ATMI (MN, USA) developed multilayered cassettes that could be coupled with automatic devices allowing medium circulation and helping with medium replacement. Another company Terumo (NJ, USA) has developed a fully automated bioreactor based on hollow-fiber technology that can allow large expansion of MSCs in a GMP-compliant system [8]. Moreover, bioreactors could help manage environmental conditions especially supplying continuous low oxygen tension which improves the growth and genetic stability of MSCs [9]. Finally, the use of bioreactors performing the entire processes is in closed systems that could allow for the production of MSCs in a class C or D room and not a class A cabinet in a class $\mathrm{B}$ room. The critical production process challenges with integrated GMP compliances starting from isolation to fill and finish are described in figure 2. Therefore, it is prudent to optimize and lock down large-scale manufacturing processes early and before commencement of Phase 3 trials. That should decrease the number of regulatory and financial hurdles from the perspective of the sponsor.

\section{Donor Bone Marrow Aspiration Program}

Donor bone marrow aspiration program needs to start only after Institutional Stem Cell Research and Therapy (ISCRT) committee approval along with university or hospital ethical committee approval in place. Donor identification and screening starts with informed consent form (ICF) with complete briefing of procedures to each of the potential donors. Every participant is evaluated for donor eligibility by their medical history, physical examinations, blood tests and Infectious disease screening as shown in process flow diagram of Figure 3. MSC proliferation and multipotency is directly proportional to age of the donors [10]. Hence, the age of the donor should be carefully considered to keep the eligible criteria within a narrow range. Critical quality parameters for bone marrow aspiration (BMA) involve use of predefined pricks using a Jamshidi needle and the quantity of BMA drawn from each prick to be defined to maintain and establish a consistent aspiration process [11]. Further, BM aspiration process affects the yield and quality of MSCs and the recommended volume of $\mathrm{BMA}$ is at least $8 \mathrm{ml}$ from one tissue site [12].

\section{Donor Cell Bank Preparation}

Donor cell bank (DCB) preparation starts after BMA and mononuclear cells (MNC) isolation by density gradient method. It is standard method for isolation of MNC from BM but density gradient method may impact on low yield of MNC [13]. MNCs should be seeded in multiples of T-75 flask and incubated in $\mathrm{C}_{2}$ incubator for 10 to 15 days to obtain $60-90 \times 10^{6}$ MSCs at P0. On the other hand, lower seeding density of $1 \times 10^{3}$ MNCs per $\mathrm{cm}^{2}$ have generated a $192,766 \pm$ 35,050 cells $/ 10^{6} \mathrm{BM}-\mathrm{MNCs}$, followed by the densities of $5,000,10,000$, and 25,000 cells $/ \mathrm{cm}^{2}(134,938 \pm 20,444,133,921 \pm 22,490$, and 108,057 $\pm 17,173$ cells $/ 10^{6} \mathrm{BM}$ MNCs) respectively [14]. However, it has been noticed that initial plating density of MNCs has great impact on the MSC yield at P0 with maximum yield obtained at lower seeding
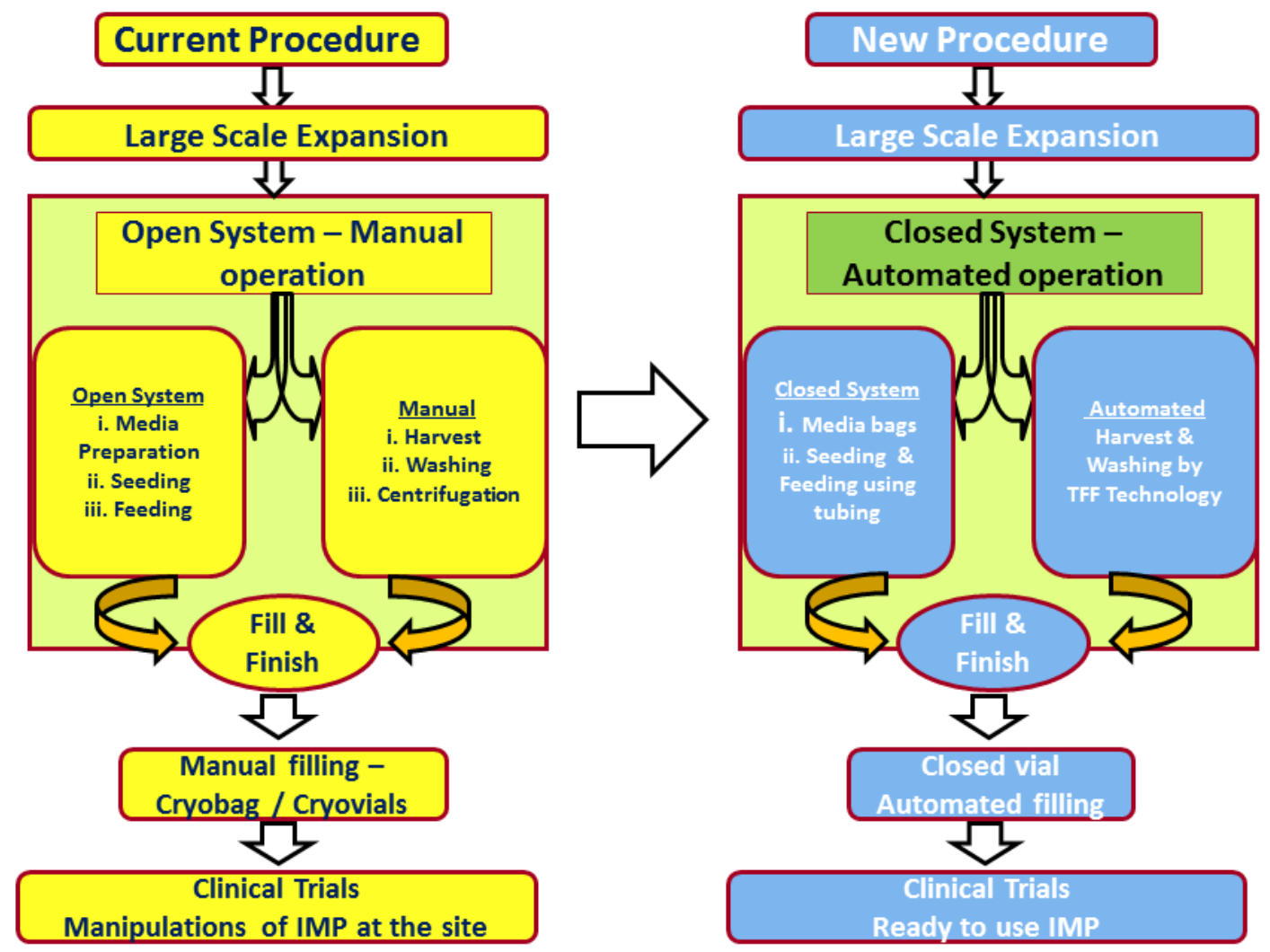

Figure 2: Translation of open process to close and automation system-Diagrammatic overview of mesenchymal stromal cell bioprocessing shifting from open system of manual operation to closed controllable system of automation to enhance GMP processing and future requirements to enter clinical trials. Abbreviations: IMPInvestigational medicinal product. 


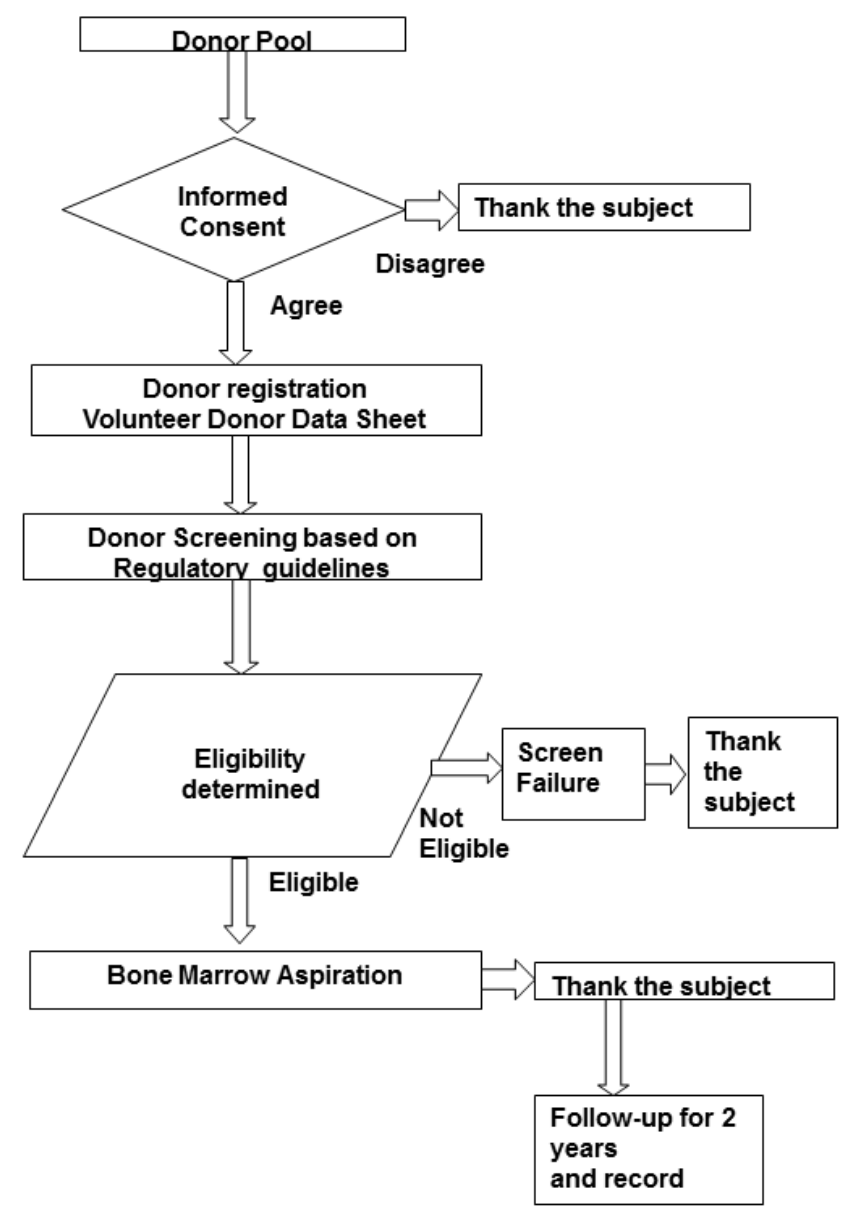

Figure 3: BM aspiration flow chart - Overview of bone-marrow aspiration flow chart.

density. Initial MNC seeding density need to be optimized based on the culture condition, product passage number. Depending upon the process and product requirements, passage number of DCB would be either passage 1 (P1) or P0. Since P0 may still have monocytes and macrophages contaminations, our recommendation would be to use the P1 cell rather P0 cells for DCB preparation. Ideally various donor cell banks can be created based on process and product requirement.

Conventional isolation process of MSC relies on the adherence of fibroblast-like cells to a plastic surface and the removal of non-adherent hematopoietic cells through frequent media changes [15]. The adherent cells contain not only heterogeneous MSC populations of immature Mesenchymal precursor cells (MPC) and more mature stromal cell types, but also other adherent non-MSC cells like osteoprogenitor cells, fat cells, reticular cells, macrophages, and endothelial cell [16,17]. There are several alternative methods available to enrich and isolate the MSCs before plating and selecting BM-MSCs through adherence to plastic dishes. Magnetic activated cell sorter (MACs) is one of the convenient methods for isolation of MSCs in recent times. Magnetic separation of selected cells is a rapid, gentle, flexible, automated, scalable and GMP amenable process. Proliferation and differentiation potential of CD271 positive MSC isolated through positive selection using MACS process has been used and was compared with MSCs derived by plastic adherence (PA) [18]. These studies show a need of better isolation technique for establishment of pre-qualified banks and for clinical or therapeutic grade production of pure MSC population [15,18]. In recent time, there have been several new techniques and strategies reported for the isolation of MSCs through surface immobilization of MSCs using Deoxyribonucleic acid (DNA) parameters, Sepax technology, nonwoven fabric filter device and PluriBead technology [13,19-21]. The development of such methodologies has made it almost mandatory to define the initial cell population in terms of their phenotype, gene expression, and secretomes profile and differentiation characteristics. The accumulated evidence indicates that the conventional isolation procedures of MSC need to be modified and adopted for MNC isolation and process the cells in a closed system to establish donor cell banks. Establishment of a through quality criteria for cell bank is of great importance in order to develop a product or subsequent cell banks from which a consistent cell product can be generated throughout the life of the original cell bank. However, these various isolation procedures of MNCs from BMA needs to be carefully analyzed as isolation procedure itself has major impact on functional activity of MSCs [22]

\section{Working Cell Bank Preparation}

The Working cell bank (WCB) preparation begins, once the DCBs are qualified and released for production process. A single vial from each donor with well characterized DCBs needs to be were thawed and cultured for one or two passages and cryopreserved to produce the initial WCB. The demand of the production process determines quantity of working stocks and adopts a reliable and reproducible freezing process using controlled rate freezing method. Validation of DCB and WCB is necessary by using a set of acceptable limits for qualifying the cell banks for production purpose. Seeding densities as well as quality of media composition which includes basal media and qualified FBS with addition of growth factors are most important factors in bringing out qualified cell bank for production process.

\section{Seed Preparation for Clinical-scale Production Batch}

When it comes to large scale production for cell therapy, one of the most important challenges is how to scale-up its manufacturing process in a cost effective manner. For a pre-defined batch size during production, a constant number of culture vessels with good growth surface area single layer Cell STACKs (CS) (Corning) or Cell Factories (CF) (Nunc) are seeded by using QC released WCB vials for clinicalscale production. A methodical screening (microscopic observation) at different interval of culture age is also necessary to monitor the cell confluency as one of the process variables. Along with screening feeding schedule needs to be standardized base on the process. Over confluent cultures usually tend to undergo replicative senescence and preferable choice of confluency within $80-90 \%$ may minimize the cellular senescence and cell cycle growth arrest [23].

\section{Clinical-scale Production}

For clinical or commercial purposes, it is necessary to produce a very large number of cells per production run. Scaleup can be achieved by increasing the batch size or number of layers per vessel to a manageable size for manufacturing. A traditional 10-layer vessel of Cell Factories (CF) or Cell STACKS (CS) provides a large growth surface of $6360 \mathrm{~cm}^{2}$ by multi-layered stacks in single vessel. They provide easy handling and low risk of contamination. The seed harvest should be immediately followed by expansion of designated set of lot size in multiple layers of CF or CS culture vessels of 10 or 40 units as clinical scale batch. Once the cultures reach required confluency cells are detached through washing the culture vessels with DPBS and followed by incubation with $0.2 \%$ of trypsin EDTA at $37^{\circ} \mathrm{C}$. The detached cells are neutralized 
through trypsin neutralization solutions (TNS) which neutralize proteases or trypsin. Trypsinized cells are recovered by centrifugation and re-suspended in complete medium at a concentration of 1-3 million per $\mathrm{ml}$. Seeding in all units of production vessels should be completed within 10-20 minutes after process initiation to prevent cell attachment to the walls of the vessels. One of the major key variables to get consistency in confluency depends on the distribution of cells in all the layers of the Cell STACKS. The batch size of each of the production batch should be constant in terms of number of production vessels.

\section{Pre-harvest Preparation}

A day prior to harvest, cryo-labels and cryobags need to be air evacuated and labeled appropriately and tube sealers needs to be charged properly. If the product presentation is in vials then ensure various vial container and appropriate stoppers and seals, hand sealer and sterilization of seals and printed labels are prepared a day before harvest [24]. The filling machine need to be check and qualified at least a day before using. Another important step for clinical scale harvesting is the preparation and filtration of TNS and freezing media. All these activities need to be performed a day before or few hours before the harvest of the IMP in GMP production suites. A pre-harvest process and material check list verification will synchronize the system and process during large-scale harvesting.

\section{Harvest Process}

Ideally production batch should have single harvest of pooled cells of all the culture vessels that goes in all the cryobags or cryovials of single dose. This ensures the product uniformity and consistency in all the cryobag or cryovials pertaining to that batch. Clinical-scale harvesting of 10 or 40 layers cultures vessels starts with DPBS washing after decanting or aspirating the spend media from vessels. A 5-10 ml of spent media needs to be collected from each of the vessel and analyzed for the spent media characteristics. Warm $37^{\circ} \mathrm{C} 0.25 \%$ trypsin EDTA should be added to each of the production vessels and incubated for 3 to 5 minutes. The culture vessels are tapped gently to dislodge most of the cells to form uniform cell suspension immediately neutralized by adding half of the intended volume of TNS and the cells are collected in collection container. The production vessel is then rinsed with another half volume of TNS for efficient recovery of cells from all the layers of CS or CFs. The detached single cell suspension of MSCs collected in centrifuge tubes and pellet is recovered through centrifugation. It is important to note that harvesting process should be completed within $2 \mathrm{~h}$ otherwise the final product will have impact on viability and differentiation [25].

\section{Post-trypsinization Process}

Large scale cultured and expanded cells are harvested and washed with DPBS and centrifuged to reduce the BSA levels in the IMP. The optimization of post culture processing step need strategic volume reduction approaches to retain the viability and to minimize the BSA level in final product. It is essential to prepare a cell based product with high purity levels by reducing the BSA content to about $<50 \mathrm{ng} / \mathrm{ml}$. Residual FBS components in terms of BSA needs to be removed through one or two DPBS washing [26]. Several technologies are available for the downstream processing steps of cell therapy products and most of them are still being evaluated for commercialization purpose [27]. In fact, Automated washing machine (cytomate) has shown $95 \%$ post washing viability of cells, but low cell recovery of $85.3 \%[28,29]$. In centrifugation based Cell processor (COBE 2991) shown a viable cell recovery of $73 \%$ compared to cytomate of 95\% [30-32]. Closed Continuous Centrifuge system $\mathrm{kSep}^{\mathrm{m}}$ can also be used to develop an integrated cell therapy manufacturing process at stage for cell washing, buffer change and to minimize the manual operations and validation requirements $[33,34]$. Tangential flow filtration (TFF) and sequential differential centrifugation technologies are other options for cell harvesting however these systems require extensive optimization and validation for processing large lot sizes to ensure that all microcarriers or particulates are removed from final product [35,36]. In contrast, manual operation results in inconsistency, manual error, and excessive shear stress due to centrifugation, contamination risk and are time consuming process. Future optimization studies needs sterile closed volume reduction post-harvest process either by low shear tangential flow or by continuous centrifugation or by integration of both systems for efficient cell washing.

\section{Fill and Finish}

Commercial success of cell therapy requires a consistency in cell number, viability and efficacy of the product. The current transition from open system to closed automated end to end fill and finish needs to be performed in a replicable, controllable way. Conventional open process are still in use, because of usage of cryobag for cryopreservation of MSC [37] but the use of cryo-bag increase additional preparative steps and the manual filling activities are usually performed by more than one trained personnel in multiple bio-safety cabinets within the GMP production facility. The most common manual errors during fill and finish are; filling inappropriate cell doses in cryobags because of volumetric error, and excess time taken to complete filling process (more than 30 minutes), delay or lack of co-ordination in placing cryobags for $\mathrm{CRF}$, selection of inappropriate CRF program for run. Recently closed semi-automated or full automation filling instruments are available for freezing cell therapy product and require a class 100 clean rooms. However, integration of automation for fill and finish step in cell therapy products can be easily upgraded to vials, as many conventional pharma and bio-pharma products in vials has already proven safe and are in regular usage for clinical and as commercial application [38]. The screw cap based cryovial of polypropylene container has challenge of container-closer integrity, extractable and scalability. A sterile Daikyo Crystal Zenith vial and a stopper offer solution to overcome the above challenge for ultra-low cryopreservation and transportation of cell therapy product [24]. The shift to pharmaceutical vial and automated compatible filling systems would enable filling several hundred doses of cells per production batch. Filling station from waston-marlow (Flexicon) filling machine with West Pharma or Aseptic technologies enables semi-automated to fully automated systems [24,39].

\section{Cryopreservation}

Effective and efficacious therapeutic advantage of BM-MSCs can be accelerated, maintained and translated into the clinical application by effective cryopreservation process. Cryopreservation media plays an important role to maintain stability, increase shelf life period without losing any functional characteristics of MSCs. Presently standard practice is cryopreserving MSCs in Plasma-Lyte A supplemented with albumin and a cryoprotectant such as DMSO and/or dextran [40]. Moreover many cryopreservation protocols uses 10\% DMSO as cryoprotective agent for MSCs [35,41].The usage of $10 \%$ DMSO enhances post-thaw manipulation during administration of drug. Further, in-house cryopreservation formulations require USP grade or cGMP grade reagents to satisfy the safety requirements when used as therapeutic parental drug. Thus cryopreservation media used for cryopreservation of MSC requires GMP compliances, which can take care of all regulatory hurdles for cell therapy products. It can be possible by using the commercially available GMP compliance USP grade; 
serum free, protein free media that contain low percentage of DMSO for therapeutic applications. Several serum-free cryopreservation media are available in the market as GMP-compliant products [42-45]. A few ready to use formulation for cryopreservation includes CryoStor 5 (CS 5), IBMT ${ }^{\text {stem }}$, and Cryopan [46] with different concentration of DMSO. Although, 10\% DMSO does not alter the viability or differentiation efficiency [47] of frozen MSC, but the cryopreserved cell therapy products requires post-thaw washing to remove DMSO. The washing of thawed cells removes $>96 \%$ of DMSO, but these manipulations have several impacts on final product.

\section{Quality Control}

\section{Raw material testing}

The Quality control (QC) of cell therapy production system should ensure the suitability of raw materials for specific activities in a production setting. In most cases, raw material testing of components is not possible, as there is no definite pharmacopeia method to test the identity of materials which are used in cell therapy manufacturing. In most of the processes raw material release criteria rely on COA verification for consumables. However, appropriate quality testing and release criteria are needed for cell culture reagents and consumables as safety and purity of the cell based product would ultimately dependent on the consumables and reagents used. There is a need to develop robust testing methodologies specifically to qualify and release the critical raw materials like cell stacks, FBS, starting cell banks apart from doing general microbiological testing [48]. The raw material like bovine serum (2262), trypsin (0694) can be tested for their identity, purity, efficacy and safety based on Ph. Eur monographs. For the raw materials, which are used in the production process, must be tested for their identity, potency, purity and safety with relevant specification (E. Charton, 03/04/2013@2013 EDQM). Recently Ph.Eur. Commission was established in 2011 to setup quality requirements for cell therapy raw materials. The source, origin and suitability of each biological starting material are critical in producing the consistent and safe cell therapy product (6.1 of EMEA, GMP annex2 and EU regulation 1394/2007) [49].

\section{Intermediate product testing}

The Quality control (QC) of cell therapy production system is increasingly gaining importance, as the product needs to meet safety and efficiency in preclinical and clinical trials. Apart from the standard characterization of MSCs as plastic adherent cells, specific immune phenotypic marker expression and multi-lineage differentiation capacity, it is necessary to check immunomodulatory function, cytokine profile, stability and molecular signature through microRNA expression analysis of these cells [50]. The testing and determining specification for starting material, intermediate products and final product should be analysed during the production process. The developments of technologies, methodologies for characterization of mesenchymal stem cell for clinical applications are outlined in Figure 4. The quality of cell therapy product is governed by establishing a robust QC system for maintaining the consistency of final product during each production run.

\section{Criteria for batch qualifications}

The basic characteristics to qualify MSCs for clinical trials includes identity, purity, potency, tumourigenicity and genomic stability of these cells (stem cell based medicinal products, EMA/CAT/571134/2009, released on 14 Jan 2011). Apart from extensive safety evaluations like sterility, endotoxin, residual FBS related component like BSA removal at the end of the production batch, evaluation of cryopreserved final product for potency assay, invitro-toxicity, immune-suppressive and immunogenicity analysis are very important [51-53]. It may be ideal to measure these activities and generate the specification of product's indented biological effect and correlation of the product for clinical response.

\section{Current Challenges in Quality Testing Program and Integration of Quality Assurances}

There is no pharmacopeia (compendial method) method to test the raw material like basal media, reagents, consumables, complete media, neutralization media etc. however, in-house testing methodology and criteria for evaluation of quality parameters are in practice [54].

There are no reference standards for testing of positive and negative CD markers by flow cytometry method, differentiation and potency assay.

7AAD method of viability has a challenge correlating with the cell recovery of cryopreserved MSCs.

Implementation of PAT (Process Analytical Technology) or QbD (Quality by design) is difficult due to limited understanding and inhomogeneous scale-out systems.

There are no standard, time points and criteria for stability testing programme of the shelf life of cell therapy product.

There are no substantial standards or specification to define impurity profile on cell therapy products.

It is necessary to set the population doubling of Investigational Medicinal Product (IMP)/commercial product in clinical scale production.

\section{Quality Assurance}

The need of continuous quality assessment program for cell therapy manufacturing to maintain overall standards in assuring patient safety and drug and system efficacy through internal audits, validations, due diligence, strategic assessment, accreditations, certifications, clinical approvals etc. [55]. QA ensures the demonstration of safety standards through implementation of safe controllable, consistent, GMP amenable manufacturing and drug delivery procedures [55]. Maintaining standards for process assurance through implementing (Figure 5) Standard Operating Procedures (SOP), Process Procedures (PP), Standard Testing Procedures (STP), Out Of Specifications (OOS), Corrective and Preventive Actions (CAPA). QA also need to conduct Management Review Meetings (MRM), vendor auditing and developing a system and procedures for process deviation management, risk management (failure mode effect analysis), archival systems, batch records, calibration records, manpower training and assessment, equipment and facility qualifications and logs etc. The main responsibility of QA is enforcing the cGMP standards, release of batches, monitoring the process for maintaining the cGMP compliances. Some of the errors or deviations in cell therapy manufacturing can be controlled through regular training, evaluations, and corrective actions to ensure the quality performances. Analyzing the notable events of deviations, manual errors, batch failures through developing a framework of developing online database and quarterly review will ensure deviation trends for process improvements, identifying recurring events etc. to minimize the potential risk and ensures the successful function of quality assurances [56]. 


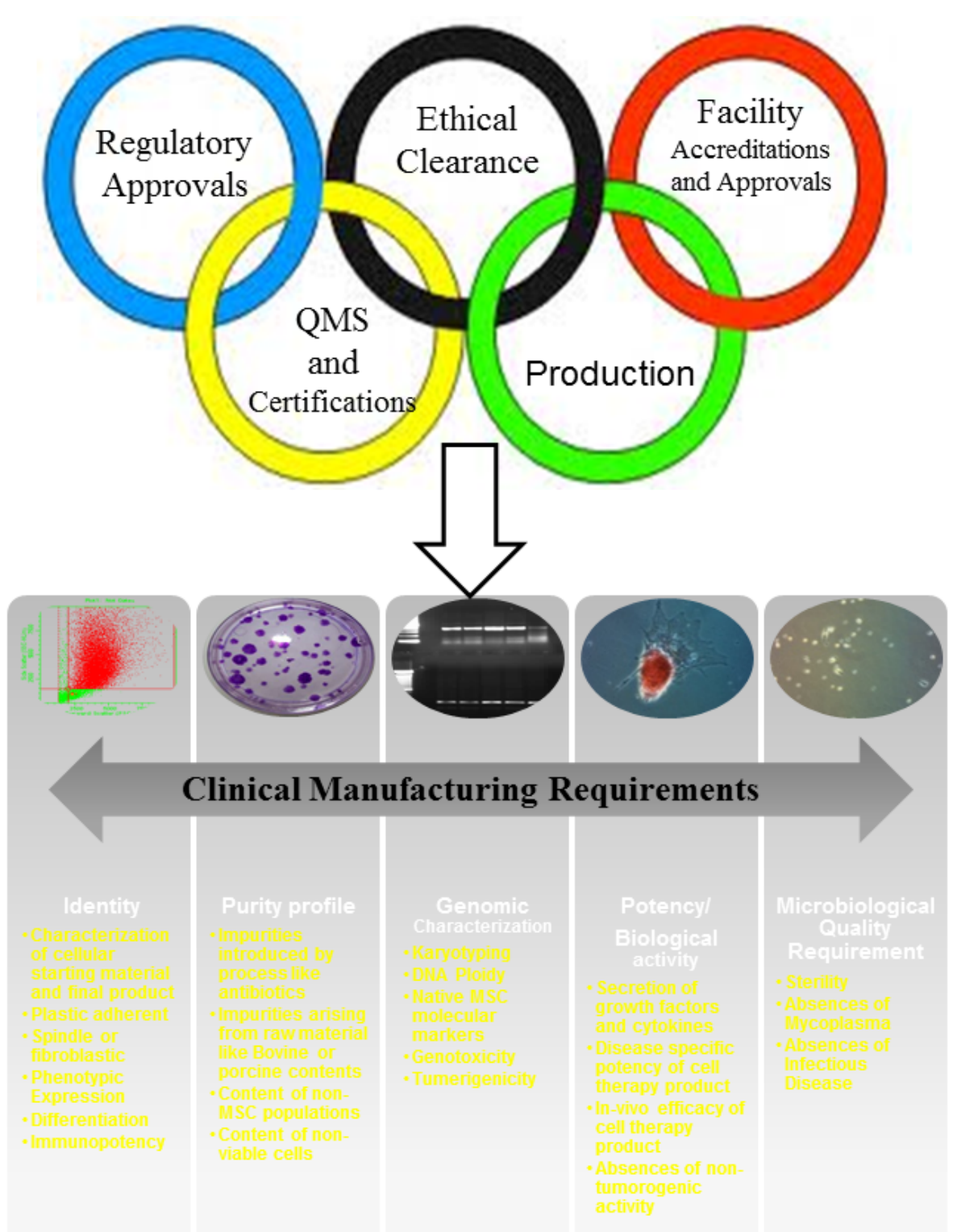

Figure 4: Characterization of cell therapy product-Overview of critical components and characterization requirement for clinical manufacturing of human mesenchymal stromal cells. Abbreviations: cGMP-current good manufacturing practice; QMS-Quality management system.

\section{Potency Assay}

The potency is the ability of the product to affect a given therapeutic result. This is an extremely important characteristic of the cellular product, which should be taken into consideration during the product development phase. It is considered an essential aspect of the quality-control system for a CT drug substance and drug product. It is performed to assure identity, purity, potency and stability of products used during all phases of clinical study as well as for commercial products. Potency testing is defined in 21 CFR Part 600.3(s) as "the specific ability or capacity of the product, as indicated by appropriate laboratory tests or by adequately controlled clinical data obtained through the administration of the product in the manner intended, to effect a given result".

The overview FDA guidelines for potency of cell products: for approval of a biologics license application (BLA), CT products must meet the requirements of safety, purity, and potency prescribed in the above regulations. However, as stated in FDA's guidance on CGT potency testing, "FDA regulations allow for considerable flexibility in determining the appropriate measurement(s) of potency for each product." As is typical, the FDA evaluates the adequacy of potency tests for such cutting-edge products case by case.

\section{Manufacturing Challenges in Cell Therapy}

Several authors have presented the challenges from regulatory, drug delivery point, noticing the product quality, logistic issue, storage and translational issues etc. [57,58]. Manufacturing of cell therapy products needs to overcome the following process as well as technical challenges.

1. Lack of in-process control to decide the set of criteria or baseline to predict the harvest time. 


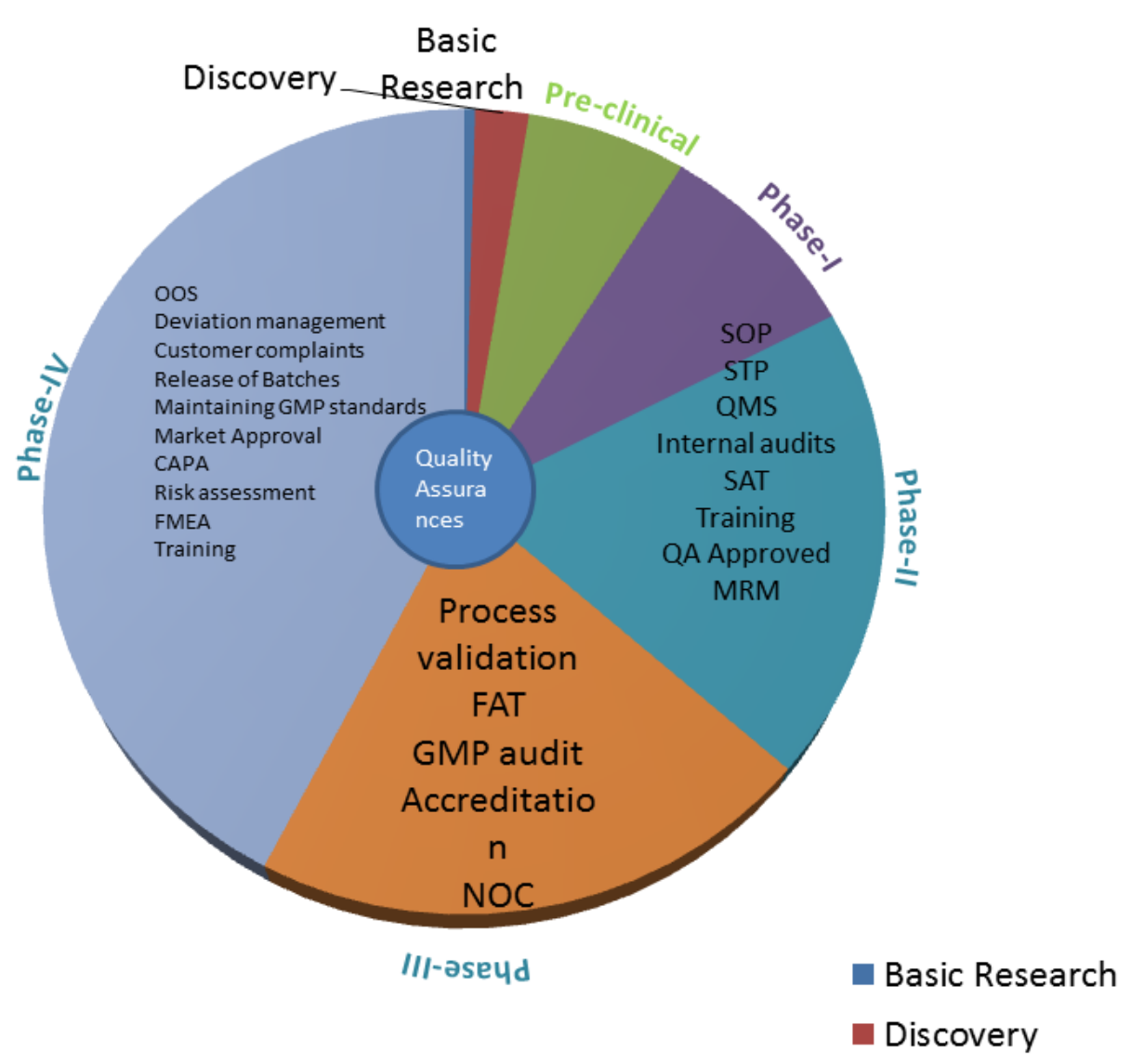

Figure 5: Roll of Quality Assurance in cell therapy product development-The Quality Assurance Department role in cell therapy product development to post launch of product. Abbreviations: OOS: Out-Of Specification; CAPA: The Corrective and Preventive Action; FMEA: Failure Mode and Effects Analysis; FAT: Field Acceptance Testing; SOP: Standard Operating Procedure; STP: Standard Technical Procedures; QMS: Quality management system; SAT: Site Acceptance Testing; MRM: Management Review Meetings.

2. Process monitoring tools of physiological parameters $\mathrm{pO}_{2}$, pHs etc. are difficult to monitor and integrate into multi-layer culture systems.

3. There is no option for in-process testing of cells of large-scale batch through sampling and no provisional design or device for sampling.

4. Use of Bioreactors for large scale is advantageous as it is a completely closed system but still needs to evaluate and streamline the process. Further manufactured MSC needs to validate for their characteristics and therapeutic potential.

5. Cell detachment through trypsinization and subsequent neutralization and complete harvest process is time consuming and time dependent process. Any delay in manual operations/ manipulation will drastically affect the quality of MSCs.

6. Requires skilled or technically experienced personals and frequent training and assessment should be part of the system as most of the manufacturing processes manipulations are performed in open system.

7. It is difficult to automate the filling procedure of cryo-bag of different doses in a single batch.

8. Cell recovery and post-harvesting washing to reduce the BSA through multiple centrifugation steps carries a centrifugal stress on cells causing decrease in cell viability. Non-centrifugal based Tangential Flow filtration (TFF) or continuous closed centrifugation system are in the initial stage of development for commercial applications in cell therapy industry.

9. Minor changes in raw material (lot number) have impact on cell quality as well as decrease the robustness and consistency of process.

10. Media filtration requires cost effective, viral free, closed and integrated system for clinical production batches are challenging.

11. Currently most of the aseptic processing in clean room is manual and 2 or 3 fold increase in batch size requires the additional manpower and space, which increased risk of contamination in clean room.

12. It is difficult to have clinical grade raw materials for the manufacturing, most of the raw materials used for cell therapy are research grade or culture grade.

13. The major challenge in establishment of bio-similarity when the existing donor bank is exhausted or expired.

\section{Conclusions}

A rapid expansion of growth of BM MSC use in terms of its use in to various pre-clinical diseases model as well as human clinical studies 
Citation: Kolkundkar U, Gottipamula S, Majumdar AS (2014) Cell Therapy Manufacturing and Quality Control: Current Process and Regulatory Challenges. J Stem Cell Res Ther 4: 230. doi:10.4172/2157-7633.1000230

Page 9 of 10

has opened up a new opportunity to treat degenerative disease. Recent demonstration of safety of using these cells in multiple clinical trials has increased the expectations of the potential for therapeutic benefit [58]. There are numerous reviews written on regulatory compliances and manufacturing process and MSC field is translating to clinical demonstration and further penetration into market. The development should proceed to ensure the safety and quality with scientific evidence for evaluation of product efficacy without any compromise or rush to meet or promote/conclusion of market authorization, which may later adversely effect. Considering the challenges posed by cell therapy as a complex living, dynamic product by itself, and developing inprocess controls needs a collaborative, integrated approach for indepth analysis and thorough validation standards. It is also importance to seek expert opinion in regulatory area and scientific expertise of biological or biotechnological products for developing or addressing critical issues. Addressing all these issues in a coherent manner and by seeking support from the experts of various technical domains would facilitates the entrance of cellular therapeutics in a reasonable time.

\section{Author's Contribution}

Udaykumar Kolkundkar: First and corresponding author, Made significant contribution in conception and design, provision of study materials, data re-analysis and interpretation, drafting and revising manuscript and final approval.

Sanjay Gottipamula: Second author and made significant contribution in manuscript preparation, provision of study materials, collection and assembly of data, data analysis and interpretation.

Anish Sen Majumdar: Third author and made significant contribution in reviewing the manuscript, cross checking the analysis and interpretation of the data and final approval of manuscript.

\section{References}

1. Mason C, McCall MJ, Culme-Seymour EJ, Suthasan S, Edwards-Parton S, et al. (2012) The global cell therapy industry continues to rise during the second and third quarters of 2012. Cell Stem Cell 11: 735-739. [PubMed]

2. Brindley DA, Reeve BC, Sahlman WA, Bonfiglio GA, Davie NL, et al. (2011) The impact of market volatility on the cell therapy industry. Cell Stem Cell 9: 397-401. [PubMed]

3. Mason C, Brindley DA, Culme-Seymour EJ, Davie NL (2012) Cell therapy industry: billion dollar global business with unlimited potential. Regen Med 6: 265-272. [PubMed]

4. Baron F, Storb R (2012) Mesenchymal stromal cells: a new tool against graftversus-host disease? Biol Blood Marrow Transplant 18: 822-840. [PubMed]

5. Mason C, Hoare M (2007) Regenerative medicine bioprocessing: the need to learn from the experience of other fields. Regen Med 1: 615-623. [PubMed]

6. Mason C, Hoare M (2007) Regenerative medicine bioprocessing: building a conceptual framework based on early studies. Tissue Eng 13: 301-311. [PubMed]

7. Godara P, McFarland CD, Nordon RE (2010) Design of bioreactors for mesenchymal stem cell tissue engineering. J Chem Technol Biotechnol 83: 408-420.

8. Rojewski MT, Fekete N, Baila S, Nguyen K, Fürst D, et al. (2012) GMPcompliant isolation and expansion of bone marrow-derived MSCs in the closed automated device Quantum Cell Expansion system. Cell Transplant 22: 19812000. [PubMed]

9. Estrada JC, Albo C, Benguira A, Dopazo A, Lopez-Romero P, et al. (2012) Culture of human mesenchymal stem cells at low oxygen tension improves growth and genetic stability by activating glycolysis. Cell Death Differ 19: 743755. [PubMed]

10. Stolzing A, Jones E, McGonagle D, Scutt A (2008) Age-related changes in human bone marrow-derived mesenchymal stem cells: consequences for cell therapies. Mech Ageing Dev 129: 163-173. [PubMed]
11. Trewhitt KG (2001) Bone marrow aspiration and biopsy: collection and interpretation. Oncol Nurs Forum 28: 1409-1415. [PubMed]

12. Fennema EM, Renard AJ, Leusink A, van Blitterswijk CA, de Boer J (2009) The effect of bone marrow aspiration strategy on the yield and quality of human mesenchymal stem cells. Acta Orthop 80: 618-621. [PubMed]

13. Posel C, Moller K, Frohlich W, Schulz I, Boltze J, et al. (2012) Density gradient centrifugation compromises bone marrow mononuclear cell yield. PLoS One 7: e50293. [PubMed]

14. Sotiropoulou PA, Perez SA, Salagianni M, Baxevanis CN, Papamichail M (2006) Characterization of the optimal culture conditions for clinical scale production of human mesenchymal stem cells. Stem Cells 24: 462-471. [PubMed]

15. Jones EA, Kinsey SE, English A, Jones RA, Straszynski L, et al. (2002) Isolation and characterization of bone marrow multipotential mesenchymal progenitor cells. Arthritis Rheum 46: 3349-3360. [PubMed]

16. Simmons PJ, Torok-Storb B (1991) Identification of stromal cell precursors in human bone marrow by a novel monoclonal antibody, STRO-1. Blood 78: 5562. [PubMed]

17. Seshi B, Kumar S, Sellers D (2000) Human bone marrow stromal cell: coexpression of markers specific for multiple mesenchymal cell lineages. Blood Cells Mol 26: 234-246. [PubMed]

18. Kuci S, Kuci Z, Kreyenberg H, Deak E, Putsch K, et al. (2010) CD271 antigen defines a subset of multipotent stromal cells with immunosuppressive and Iymphohematopoietic engraftment-promoting properties. Haematologica 95: 651-659. [PubMed]

19. Guo KT, SchAfer R, Paul A, Gerber A, Ziemer G, et al. (2006) A new technique for the isolation and surface immobilization of mesenchymal stem cells from whole bone marrow using high-specific DNA aptamers. Stem Cells 24: 22202231. [PubMed]

20. Guven S, Karagianni M, Schwalbe M, Schreiner S, Farhadi J (2012) Validation of an automated procedure to isolate human adipose tissue-derived cells by using the Sepax $(R)$ technology. Tissue Eng Part C Methods 18: 575-582. [PubMed]

21. Ito K, Aoyama T, Fukiage K, Otsuka S, Furu M (2010) A novel method to isolate mesenchymal stem cells from bone marrow in a closed system using a device made by nonwoven fabric. Tissue Eng Part C Methods 16: 81-91. [PubMed]

22. Seeger FH, Tonn T, Krzossok N, Zeiher AM, Dimmeler S (2007) Cell isolation procedures matter: a comparison of different isolation protocols of bone marrow mononuclear cells used for cell therapy in patients with acute myocardial infarction. Eur Heart J 28: 766-772. [PubMed]

23. Ho JH, Chen YF, Ma WH, Tseng TC, Chen MH, et al. (2011) Cell contact accelerates replicative senescence of human mesenchymal stem cells independent of telomere shortening and p53 activation: roles of Ras and oxidative stress. Cell Transplant 20: 1209-1220. [PubMed]

24. Woods EJ, Bagchi A, Goebel WS, Vilivalam VD, Vilivalam VD (2010) Container system for enabling commercial production of cryopreserved cell therapy products. Regen Med 5: 659-667. [PubMed]

25. Sohn HS, Heo JS, Kim HS, Choi Y, Kim HO (2013) Duration of in vitro storage affects the key stem cell features of human bone marrow-derived mesenchymal stromal cells for clinical transplantation. Cytotherapy 15: 460-466. [PubMed]

26. Gottipamula S, Muttigi MS, Chaansa S, Ashwin KM, Priya N, et al. (2013) Large-scale expansion of pre-isolated bone marrow mesenchymal stromal cells in serum-free conditions. J Tissue Eng Regen Med. [PubMed]

27. Rafiq QA, Coopman K, Hewitt CJ (2013) Scale-up of human mesenchymal stem cell culture: current technologies and future challenges. Curr Opin Chem Eng 2: 8-16

28. Giancola R, Olioso P, Di Riti M, Capone A, Contento A (2008) Evaluation of an automated closed fluid management device for processing expanded cytokineinduced killer cells to use in immunotherapy programs for cancer. Transfusion 48: 629-639. [PubMed]

29. Lemarie C, Calmels B, Malenfant C, Arneodo V, Blaise D (2005) Clinica experience with the delivery of thawed and washed autologous blood cells, with an automated closed fluid management device: CytoMate. Transfusion 45: 737-742. [PubMed]

30. Ayello J, Hesdorffer C, Reiss RF (1995) A semiautomated technique for volume reduction of stem cell suspensions for auto-transplantation. J Hematother 4 545-549. [PubMed] 
Citation: Kolkundkar U, Gottipamula S, Majumdar AS (2014) Cell Therapy Manufacturing and Quality Control: Current Process and Regulatory Challenges. J Stem Cell Res Ther 4: 230. doi:10.4172/2157-7633.1000230

31. Calmels B, Houze P, Hengesse JC, Ducrot T, Malenfant C, et al. (2003) Preclinical evaluation of an automated closed fluid management device: Cytomate, for washing out DMSO from hematopoietic stem cell grafts after thawing. Bone Marrow Transplant 31: 823-828. [PubMed]

32. Torrabadella M, Olive T, Ortega JJ, Massuet L (2000) Enhanced HPC recruitment in children using $L V L$ and a new automated apheresis system. Transfusion 40: 404-410. [PubMed]

33. Judson G, Jones A, Kellogg R, Buckner D, Eisel R, et al. (2000) Closed continuous-flow centrifuge. 1968. Ther Apher 4: 91-94. [PubMed]

34. Robinet E, Roubi N, Certoux JM, Petracca B, Rousseau E (1999) Preparation of cell therapy products: contribution of closed systems. Transfus Clin Biol 6: 409-417. [PubMed]

35. Rowley J, Abhraham EAC (2012) Meeting Lot-Size challenges of manufacturing Adherent cells for Therapy. Bio Process International 10: 16-22.

36. Rowley JA (2010) Developing cell therapy biomanufacturing processes Chemical Engineering Progress 11: 50-55.

37. Heidemann R, Lunse S, Tran D, Zhang C (2010) Characterization of cellbanking parameters for the cryopreservation of mammalian cell lines in 100-mL cryobags. Biotechnol Prog 26: 1154-1163. [PubMed]

38. Zuleger B, Werner U, Kort A, Glowienka R, Wehnes E, et al. (2012) Duncan $\mathrm{D}$ : Container/Closure Integrity Testing and the Identification of a Suitable Vial/ Stopper Combination for Low-Temperature Storage at -80 \{degrees\} C. PDA J Pharm Sci Technol 66: 453-465. [PubMed]

39. Thilly J, Conrad D, Vandecasserie C (2006) Aseptic Filling of Closed, Ready to Fill Containers. Pharmaceutical Engineering 26: 66

40. Pal R, Hanwate M, Totey SM (2008) Effect of holding time, temperature and different parenteral solutions on viability and functionality of adult bone marrowderived mesenchymal stem cells before transplantation. J Tissue Eng Regen Med 2: 436-444. [PubMed]

41. Thirumala S, Zvonic S, Floyd E, Gimble JM, Devireddy RV (2005) Effect of various freezing parameters on the immediate post-thaw membrane integrity of adipose tissue derived adult stem cells. Biotechnol Prog 21: 1511-1524. [PubMed]

42. Grein TA, Freimark D, Weber C, Hudel K (2010) Alternatives to dimethylsulfoxide for serum-free cryopreservation of human mesenchymal stem cells. Int J Artif Organs 33: 370-380. [PubMed]

43. Clarke DM, Yadock DJ, Nicoud IB, Mathew AJ, Heimfeld S (2009) Improved post-thaw recovery of peripheral blood stem/progenitor cells using a novel intracellular-like cryopreservation solution. Cytotherapy 11: 472-479. [PubMed]

44. Ginis I, Grinblat B, Shirvan MH (2012) Evaluation of bone marrow-derived mesenchymal stem cells after cryopreservation and hypothermic storage in clinically safe medium. Tissue Eng Part C Methods 18: 453-463. [PubMed]
45. Stylianou J, Vowels M, Hadfield K (2006) Novel cryoprotectant significantly improves the post-thaw recovery and quality of HSC from $\mathrm{CB}$. Cytotherapy 8 : 57-61. [PubMed]

46. Zeisberger SM, Schulz JC, Mairhofer M, Ponsaerts P, Wouters G (2010) Biological and physicochemical characterization of a serum- and xeno-free chemically defined cryopreservation procedure for adult human progenitor cells. Cell Transplant 20: 1241-1257. [PubMed]

47. Thirumala S, Goebel WS, Woods EJ (2009) Clinical grade adult stem cell banking. Organogenesis 5: 143-154. [PubMed]

48. Hess RD, Weber F, Watson K, Schmitt S (2012) Regulatory, biosafety and safety challenges for novel cells as substrates for human vaccines. Vaccine 30 : 2715-2727. [PubMed]

49. Migliaccio G, Pintus C (2013) Role of the EU Framework in Regulation of Stem Cell-Based Products. Adv Biochem Eng Biotechnol 130: 287-299. [PubMed]

50. Stroncek DF, Jin P, Ren J, Feng J, Castiello L (2010) Quality assessment of cellular therapies: the emerging role of molecular assays. Korean $\mathrm{J}$ Hemato 45: 14-22. [PubMed]

51. Bravery CA, Carmen J, Fong T, Oprea W, Hoogendoorn KH (2013) Potency assay development for cellular therapy products: an ISCT review of the requirements and experiences in the industry. Cytotherapy 15: 9-19. [PubMed]

52. Bailey AM (2012) Balancing tissue and tumor formation in regenerative medicine. Sci Transl Med 4: 128-147. [PubMed]

53. Menard C, Tarte K (2013) Immunoregulatory properties of clinical grade mesenchymal stromal cells: evidence, uncertainties, and clinical application. Stem Cell Res Ther 4: 64. [PubMed]

54. Schneider CK, Salmikangas P, Jilma B, Flamion B, Todorova LR (2010) Challenges with advanced therapy medicinal products and how to meet them. Nat Rev Drug Discov 9: 195-201. [PubMed]

55. Du Moulin GC, Pitkin Z, Shen YJ, Conti E, Stewart JK (1994) Overview of a quality assurance/quality control compliance program consistent with FDA regulations and policies for somatic cell and gene therapies: a four year experience. Cytotechnology 15: 365-372. [PubMed]

56. McKenna D Jr, Kadidlo D, Sumstad D, McCullough J (2003) Development and operation of a quality assurance system for deviations from standard operating procedures in a clinical cell therapy laboratory. Cytotherapy $5: 314$ 322. [PubMed]

57. Preti RA (2001) Challenges associated with the development, manufacturing, and delivery of cellular medicines. Cancer J 7: S62-66. [PubMed]

58. Weber DJ (2008) Regulatory considerations for manufacturing and delivery of cell-based therapies for cardiovascular indications. J Cardiovasc Transl Res 1 196-200. [PubMed] 